\title{
Noninvasive respiratory support via nasal cannula in premature infants: Is it really safe?
}

\author{
Mehmet Büyüktiryaki, Nilüfer Okur, Gülsüm Kadıoğlu-Şimşek, Hayriye Gözde Kanmaz, \\ Fuat Emre Canpolat \\ Division of Neonatology, Zekai Tahir Burak Maternity Training Hospital, Ankara, Turkey. E-mail: mbuyuktiryaki@yahoo.com \\ Received: 28th December 2017, Revised: 6th January 2018, Accepted: 13th March 2018
}

SUMMARY: Büyüktiryaki M, Okur N, Kadıoğlu-Şimşek G, Kanmaz HG, Canpolat FE. Noninvasive respiratory support via nasal cannula in premature infants: Is it really safe? Turk J Pediatr 2019; 61: 307-310.

With this observational study we attempted to assess whether nasal cannulas originally used to administer high flow could be effectively used as an interface to provide ventilator generated noninvasive respiratory support. Preterm infants whose gestational ages between $26^{0 / 7}$ and $29^{6 / 7}$ weeks with respiratory instability who initially received noninvasive respiratory support with binasal prongs and then switched to nasal cannula with attending physician's decision were included. Six infants $(27 \%)$ needed intubation and mechanical ventilation while getting noninvasive support via nasal cannula, whereas this was not observed during noninvasive ventilation via short binasal prongs $(p=0.02)$. Despite the nasal cannula being easy to use and well tolerated by the preterm infant, it is not as effective as the short binasal prong when it is used as an interface in a mechanical ventilator that provides noninvasive respiratory support other than its own equipment.

Key words: nasal cannula, noninvasive respiratory support failure, premature infant, respiratory distress syndrome.

Advances in the understanding of the physiologic aspects of using noninvasive ventilation (NIV) through different interfaces and ventilator modalities have improved patient-machine interaction, thus enhancing favorable NIV outcomes. ${ }^{1-4}$ Since the introduction of nasal continuous positive airway pressure (NCPAP), several interfaces have been developed to transmit pressure. ${ }^{5}$ The most commonly used to deliver NCPAP are prongs and masks. ${ }^{5}$ The use of nasal cannulas (NC) is steadily increasing. Short binasal prongs and nasal masks are effective interfaces in NCPAP application. ${ }^{5,6}$ However NCPAP interfaces may lead to nasal mucosal damage or discomfort in the preterm infant. Nasal cannulas are small, narrow and conical tubes, and are commonly shorter than $1 \mathrm{~cm}$; furthermore, they are placed into both nostrils without causing any obstruction therefore they are thought to improve patient comfort. ${ }^{7}$
The aim of this study was to share our observations about the use of NC as interface, with NIV respiratory support through mechanical ventilator.

\section{Material and Methods}

This observational study was conducted between 01.04.2016 and 01.07.2016 in a tertiary neonatal intensive care unit. Preterm infants with a gestational age of $26^{0 / 7}-29^{6 / 7}$ weeks, who recovered from respiratory distress syndrome (RDS) yet still required respiratory support due to respiratory instability were assessed for eligibility. Patients who had congenital anomalies, hemodynamic instability, congenital heart defects and required mechanical ventilation during the first seven days of life were excluded. The study was reviewed and approved by an institutional review board, and that participation involved informed consent.

The study was presented as poster at the 2nd Congress of Joint European Neonatal Societies (JENS), 31 October- 04 November 2017, Venice, Italy; and at the 25th Turkish National Neonatology Congress (UNEKO) Congress, 12-16 April 2017, Antalya, Turkey. 
Table I. Comparison of Blood Gas and Nasal Continuous Positive Airway Pressure Failure.

\begin{tabular}{llccc}
\hline Parameters & & $\begin{array}{c}\text { Nasal cannulas } \\
(\mathrm{N}=22)\end{array}$ & $\begin{array}{c}\text { Binasal prong } \\
(\mathrm{N}=22)\end{array}$ & $\mathrm{p}$ \\
\hline First day & $\mathrm{pH}$ & $7.26 \pm 0.05$ & $7.29 \pm 0.08$ & 0.157 \\
& $\mathrm{pCO}_{2}(\mathrm{mmHg})$ & $58 \pm 9.91$ & $49 \pm 9.89$ & 0.001 \\
& $\mathrm{FiO}_{2}(\%)$ & $32 \pm 6.17$ & $28 \pm 5.60$ & 0.002 \\
Second day & $\mathrm{pH}$ & $7.28 \pm 0.05$ & $7.31 \pm 0.05$ & 0.108 \\
& $\mathrm{pCO}_{2}(\mathrm{mmHg})$ & $60 \pm 9.47$ & $50 \pm 7.43$ & 0.002 \\
& $\mathrm{FiO}_{2}(\%)$ & $32 \pm 8.10$ & $28 \pm 5.72$ & 0.000 \\
Third day & $\mathrm{pH}$ & $7.26 \pm 0.05$ & $7.30 \pm 0.05$ & 0.050 \\
& $\mathrm{pCO}_{2}(\mathrm{mmHg})$ & $63 \pm 10.60$ & $50 \pm 8.59$ & 0.002 \\
& $\mathrm{FiO}_{2}(\%)$ & $35 \pm 7.60$ & $27 \pm 5.86$ & 0.014 \\
NCPAP failure, & $\mathrm{n}(\%)$ & $6(27.3)$ & $0(0)$ & 0.021 \\
\hline
\end{tabular}

Results are presented as mean \pm standard deviation or as $\mathrm{n}(\%)$.

$\mathrm{FiO}_{2}$ : fraction of inspired oxygen, NCPAP: nasal continuous positive airway pressure, $\mathrm{pCO}_{2}$ : partial carbon dioxide pressure

Short, binasal prongs (INCA; Ackrad Labs/ Cooper Surgical, Trumbull, Connecticut, USA) and NC (Fisher \& Paykel HealthCare, Auckland, New Zealand) were used as interfaces. The appropriate size of the cannula and the prongs was chosen by taking into consideration the manufacturers' suggestions. All infants received respiratory support via short binasal prong in the first three days of life. Switching to NC from binasal prongs was performed when there was discomfort during respiratory support, nasal mucosal hyperemia, trauma, with the attending physicians' discretion. The NC interface adapted to the circuit edge of the mechanical ventilator and NCPAP mode was used in all patients. Blood gas analysis, hourly positive end-expiratory pressure (PEEP) and fraction of inspired oxygen $\left(\mathrm{FiO}_{2}\right)$ levels and mechanical ventilation (MV) requirement were recorded 72 hours before and after switching the interfaces.

Failure of non-invasive nasal respiratory support was defined as persistent apnea, respiratory acidosis ( $\mathrm{pH}<7.2$ and $\mathrm{pCO}_{2}>60 \mathrm{mmHg}$ ), $\mathrm{FiO}_{2}$ requirement $>50 \%$, PEEP requirement exceeding $8 \mathrm{cmH}_{2} \mathrm{O}$ to have target $\mathrm{SpO}_{2}$ levels, severe respiratory distress and pulmonary hemorrhage under NIV.

Statistical analysis

Statistical analyses were performed with SPSS 21 for Windows (IBM SPSS Statistics, Chicago,
IL, USA). Chi-square or Fisher's exact test was used for comparison of categorical variables as appropriate. Differences between the groups concerning continuous variables were compared by Student's t test and Wilcoxon test where appropriate. A p value of $<0.05$ was considered statistically significant.

\section{Results}

A total of 59 preterm infants were admitted during the study period. Six $(10.1 \%)$ of them died in the first three days of life, $10(16.9 \%)$ could not be extubated and in 21 (35.5\%) patients' interfaces did not switch. Finally, a total of $22(37.2 \%)$ infants were included to the study and analyzed. The mean gestational age was $28 \pm 2$ weeks, and the mean birth weight was $1,086 \pm 311 \mathrm{~g}$. The $5^{\text {th }}$ minute Apgar score was 7 (4-9). 14 (63\%) preterm infants required surfactant.

Failure of NIV was observed in 6 infants $(27.3 \%)$ during the use of the NC interface, whereas it was not observed during the short binasal prong use $(p=0.021)$. Reasons for failure of NIV were respiratory acidosis $(\mathrm{pH}$ $<7.20)$ and hypercarbia $\left(\mathrm{PCO}_{2}>65 \mathrm{mmHg}\right)$ in three infants, apnea (the need for mask ventilation $\geq 2$ times $/ h$ ) in two infants and hypoxia $\left(\mathrm{FiO}_{2}\right.$ requirement $\left.\geq 0.50\right)$ in one infant. In infants who failed NIV, half of them $(\mathrm{N}=3)$ had grade I-II intraventricular hemorrhage. Partial carbon dioxide $\left(\mathrm{pCO}_{2}\right)$ 
levels and the need for fractionated oxygen were significantly higher in NC period when compared with prong period (Table I). The blood $\mathrm{pH}$ was found to be slightly lower in the first two days of NC period and this difference became more profound and almost reached statistical significance on the third day (Table I). PEEP levels required were similar in both periods $\left(\mathrm{PEEP}_{\text {prong }}, 5.9 \pm 0.5 \mathrm{cmH}_{2} \mathrm{O}\right.$ and $\mathrm{PEEP}_{\text {cannula }} 6.2 \pm 0.5 \mathrm{cmH}_{2} \mathrm{O} ; \mathrm{p}=0.14$ ). Alteration of PEEP for two study periods was presented in Figure 1.

\section{Discussion}

In this observational study, the $\mathrm{pCO}_{2}$ levels and the need for $\mathrm{FiO}_{2}$ were found to be higher in preterm infants under non-invasive respiratory support with NCPAP mode of the mechanical ventilator when NC was used as interface; furthermore, a substantial NIV failure was observed.

There is growing knowledge that Heated Humidified High-Flow Nasal Cannula (HHHFNC) has a similar efficacy and safety profile, compared to other non-invasive respiratory support strategies. ${ }^{7,8}$ It has been thought that NC interface has superiorities to the short binasal prongs such as the nostrils are not completely obstructed, there is less nasal trauma, it is easier to use, it does not cause agitation, and it is well tolerated by the newborn. ${ }^{7,9,10}$ Regarding these properties, the nasal cannulas has been adapted to the instruments providing NIV support and used as interfaces in our unit by some clinicians. However there is debate about the support delivered to the patient because NCPAP involves an inspiratory and expiratory limbs providing bias flow via short binasal prongs. High flow therapy has no bias flow, there is no expiratory limb in the circuit ${ }^{7}$. Simply applying HHHFNC interface to ventilator driven CPAP delivers neither NCPAP nor high flow therapy. High $\mathrm{pCO}_{2}$ levels observed in the $\mathrm{NC}$ period in this study could be attributed to this insufficient respiratory support.

It is a known fact that HHHFNC gas flow forms positive distending pressure over $2 \mathrm{~L} /$ min. Since the pressure formed is related to many factors such as the size of the nasal cannula, the gas flow rate within the cannula, the airway size of the preterm infant and nasal

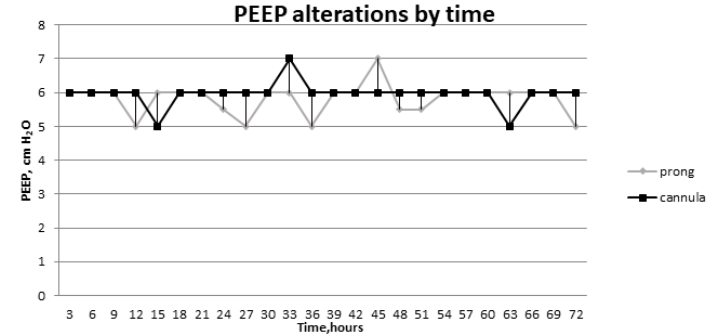

Fig. 1. PEEP alterations by time (PEEP: positive end expiratory pressure)

$\mathrm{PEEP}_{\text {prong }}, 5.9 \pm 0.5 \mathrm{cmH}_{2} \mathrm{O}$ and

$\mathrm{PEEP}_{\text {cannula }} 6.2 \pm 0.5 \mathrm{cmH}_{2} \mathrm{O} ; \mathrm{p}=0.14$

and/or oral air leaks, it is difficult to predict the pressure that would develop. ${ }^{7,8}$ While we cannot precisely determine the pressure formed during HFNC support there could be further pressure loss by adapting the NC interface to the mechanical ventilator respiration circuit and the level of the pressure adjusted on the mechanical ventilator may not be able to be successfully transmitted to the preterm infant. ${ }^{11}$

Additionally, the HFNC interface has a longer circuit compared to the short binasal prongs and this may also lead to pressure loss. We thought that the reason for higher $\mathrm{PaCO}_{2}$ levels and the higher need for $\mathrm{FiO}_{2}$ and NIV failure in preterm infants under NIV support via the NC interface may be the inadequate transmission of the pressure. Possibly we could have overcome the pressure loss by adjusting PEEP level 1-2 $\mathrm{cm} \mathrm{H}_{2} \mathrm{O}$ higher than required during CPAP with prongs after changing the interface to cannulas in some way. PEEP levels did not differ in two periods in our study. As a result, non-invasive respiratory support interfaces are produced specific to their own instruments and may be insufficient in providing respiratory support effectively when they are used in devices other than their own.

The small sample size and the observational design were the main limitations of our study.

Although the nasal cannulas are well tolerated by the newborn as an interface, it seems that it is not as effective as short binasal prongs to deliver non-invasive respiratory support driven by mechanical ventilator with a bias flow. However these findings should be supported by larger randomized controlled trials. 


\section{REFERENCES}

1. Ho JJ, Subramaniam P, Davis PG. Continuous distending pressure for respiratory distress in preterm infants. Cochrane Database Syst Rev 2015; 7: CD002271.

2. Verder H, Bohlin K, Kamper J, Lindwall R, Jonsson B. Nasal CPAP and surfactant for treatment of respiratory distress syndrome and prevention of bronchopulmonary dysplasia. Acta Paediatr 2009; 98: 1400-1408.

3. Schmölzer GM, Kumar M, Pichler G, Aziz K, O’Reilly $\mathrm{M}$, Cheung PY. Non-invasive versus invasive respiratory support in preterm infants at birth: systematic review and meta-analysis. BMJ 2013; 347: f5980.

4. Bancalari E, Claure N. Non-invasive ventilation of preterm infant. Early Hum Dev 2008; 84: 815-819.

5. De Paoli AG, Davis PG, Faber B, Morley CJ. Devices and pressure sources for administration of nasal continuous positive airway pressure (NCPAP) in preterm neonates. Cochrane Database Syst Rev 2008; 1: CD002977.

6. Say B, Kanmaz Kutman HG, Oguz SS, et al. Binasal prong versus nasal mask for applying cpap to preterm infants: a randomized controlled trial. Neonatology 2016; 109: 258-264.
7. Wilkinson D, Andersen C, O’Donnell CP, De Paoli AG, Manley BJ. High flow nasal cannula for respiratory support in preterm infants. Cochrane Database Syst Rev 2016: 2: CD006405.

8. Yoder BA, Stoddard RA, Li M, King J, Dirnberger DR, Abbasi S. Heated humidified high-flow nasal cannula versus nasal CPAP for respiratory support in neonates. Pediatrics 2013; 131: e1482-e1490.

9. Mahmoud RA, Roehr CC, Schmalisch G. Current methods of non-invasive ventilatory support for neonates. Paediatr Respir Rev 2011; 12: 196-205.

10. Taha DK, Kornhauser M, Greenspan JS, Dysart KC Aghai $\mathrm{ZH}$. High flow nasal cannula use is associated with increased morbidity and length of hospitalization in extremely low birth weight infants. J Pediatr 2016; 173: 50-55. e1.

11. Gerdes JS, Sivieri EM, Abbasi S. Factors influencing delivered mean airway pressure during nasal CPAP with the RAM cannula. Pediatr Pulmonol 2016; 51: 60-69. 